\title{
Quem são as mulheres que pensam o desenvolvimento regional no Brasil? Elementos para a formulação de uma agenda de pesquisa
}

\author{
Luciana Butzke ${ }^{1}$ \\ Ivo Marcos Theis ${ }^{2}$ \\ Caroline Laíza Negherbon ${ }^{3}$ \\ Vivian Brito ${ }^{4}$
}

\begin{abstract}
Resumo
A participação das mulheres nos Programas de Pós-Graduação em Planejamento Urbano e Regional/Demografia no Brasil foi de 43\% em 2018. Durante muito tempo, as mulheres foram invisíveis na teoria/prática do desenvolvimento. Todavia, há uma progressiva entrada delas no debate. Cabe questionar: quem são essas mulheres? Que contribuições trazem ao pensamento social e ao desenvolvimento regional na América Latina e no Brasil? Essas questões norteiam o Projeto Colaborativo Mulheres que pensam o desenvolvimento regional. O objetivo desse artigo é contextualizar o tema do desenvolvimento regional em sua relação com as mulheres, visando a formulação de uma agenda de pesquisa. A análise da produção das mulheres que pensam o desenvolvimento regional parte da ciência e da epistemologia feminista. Essas referências devem contribuir para pensar criticamente os enfoques do desenvolvimento e seus desdobramentos do ponto de vista político, bem como o compromisso da ciência/sociedade com a construção de alternativas ao desenvolvimento que se tornou hegemônico entre nós.
\end{abstract}

Palavras-chave: Desenvolvimento Regional; Pensamento Social; Gênero; Mulheres.

\begin{abstract}
The participation of women in the Graduate Programs in Urban and Regional Planning / Demography in Brazil was 43\% in 2018. For a long time women were invisible in development theory / practice. However, there is a gradual entry of women into the debate. So the questions are: Who are these women? What contribution do they bring to social thought and regional development in Latin America and Brazil? These issues guide the Colaborative Project "Women who think regional development". The purpose of this article is to contextualize the theme of regional development in its relationship with the women, aiming at the formulation of a research agenda. The analysis of the production of women who think regional development starts from the feminist science and epistemology. These references should contribute to critical thinking of development approaches and their political implicações, as well as the commitment of science/society with the building of alternatives to the development that have become hegemonic among us.
\end{abstract}

Keywords: genre; regional development; social thought; women.

\footnotetext{
${ }^{1}$ Doutora em Sociologia Política. Professora do Programa de Pós-Graduação em Desenvolvimento Regional/FURB. lbutzke@furb.br.

${ }^{2}$ Doutor em Geografia. Professor do Programa de Pós-Graduação em Desenvolvimento Regional/FURB. theis@furb.br

${ }^{3}$ Cientista social, mestranda do Programa de Pós-Graduação em Desenvolvimento Regional/FURB, carolnegherbon@hotmail.com.

${ }^{4}$ Turismóloga, doutoranda Programa de Pós-Graduação em Desenvolvimento Regional/FURB. vivianbritofoz@gmail.com.
} 


\section{Introdução}

A preocupação de quem assina este artigo com as mulheres que pensam o desenvolvimento regional tem origem nas vivências de cada um/uma, que foram sendo compartilhadas em conversas nas aulas do Programa de Pós-Graduação em Desenvolvimento Regional (PPGDR), nas reuniões do Núcleo de Pesquisa em Desenvolvimento Regional (NPDR) da Universidade Regional de Blumenau (FURB), nas conversas nos corredores e durante os cafés. A constatação de que as mulheres pouco aparecem na nossa formação acadêmica, nas referências e nas citações, nos levou ao Projeto Colaborativo Mulheres que pensam o desenvolvimento regional.

Muito do que se produziu e se praticou em nome do desenvolvimento da América Latina e no Brasil tem orientação eurocêntrica, masculina, hetero-patriarcal e branca. A história das mulheres e a história que desenharam têm sido invisibilizada e homogeneizada nas narrativas existentes. Cabe questionar: Que contribuições as mulheres trazem ao pensamento social e ao desenvolvimento regional na América Latina e no Brasil? Quem são essas mulheres? Quais são suas dificuldades e avanços? Que contribuições trazem para a teoria do desenvolvimento regional?

O objetivo desse artigo é contextualizar o tema do desenvolvimento regional em sua relação com as mulheres visando a formulação de uma agenda de pesquisa. Essa agenda de pesquisa é parte do Projeto Colaborativo Mulheres que pensam o desenvolvimento regional, cujo objetivo é mapear e divulgar a contribuição das mulheres ao pensamento social regional e à teoria do desenvolvimento regional. Consideramos a contribuição de mulheres no geral, e não apenas de mulheres inseridas nas Universidades. O Projeto Colaborativo nasceu na Universidade, mas entende que é preciso dialogar com o pensamento e a prática em todas as suas formas.

O presente artigo está dividido em cinco seções. A primeira seção, essa introdução, procura contextualizar o tema do artigo, buscando apresentar a motivação, as questões e seu objetivo. A segunda seção apresenta um panorama das mulheres nos PPG em Planejamento Urbano e Regional e Demografia no Brasil para indicar o lugar de que falamos. Na terceira seção desenvolvemos brevemente nossas inspirações (referencial teórico-metodológico) e na quarta seção a agenda de pesquisa. Na quinta e última seção tecemos algumas considerações sobre o tema e encaminhamentos. 


\section{De que lugar falamos?}

O lugar do qual falamos é do sul do Brasil, Santa Catarina, Blumenau, Universidade Regional de Blumenau (FURB), Programa de Pós-Graduação em Desenvolvimento Regional (PPGDR). O PPGDR teve início em 2000. Nós fazemos parte do Núcleo de Pesquisas em Desenvolvimento Regional (NPDR) que nasceu no dia 10 de maio de 2000. O grupo reúne professorxs ${ }^{5}$, estudantes e pessoas interessadas em refletir e atuar criticamente no ensino, pesquisa e extensão e nos processos de desenvolvimento local e regional (NPDR, 2018).

Nos Programas de Pós-Graduação em Planejamento Regional e Urbano/Demografia as mulheres somavam, em abril de 2018, 273 docentes (43\%) e os homens somavam 359 docentes (57\%). Atualmente contamos com 46 PPG em Planejamento Urbano e Regional/Demografia: os PPG em Planejamento Urbano e Regional somam 42 e 4 PPG em Demografia.

Na região norte contamos com $34 \%$ de docentes mulheres e $66 \%$ de docentes homens. Na região centro-oeste são 33\% de mulheres e 67\% de homens. A região nordeste apresenta $47 \%$ de mulheres e $53 \%$ de homens e a região sudeste $49 \%$ de mulheres e $51 \%$ de homens. Já a região sul conta com $42 \%$ de mulheres e $58 \%$ de homens (Figura 1).

${ }^{5}$ No artigo usamos o " $\mathrm{x}$ " para enfatizar o caráter plural do conjunto social (Orozco, 2017). 
Figura 1 - Localização dos PPG em Planejamento Urbano e Regional/Demografia e porcentagem de docentes homens e mulheres por IES e por região, 2018.

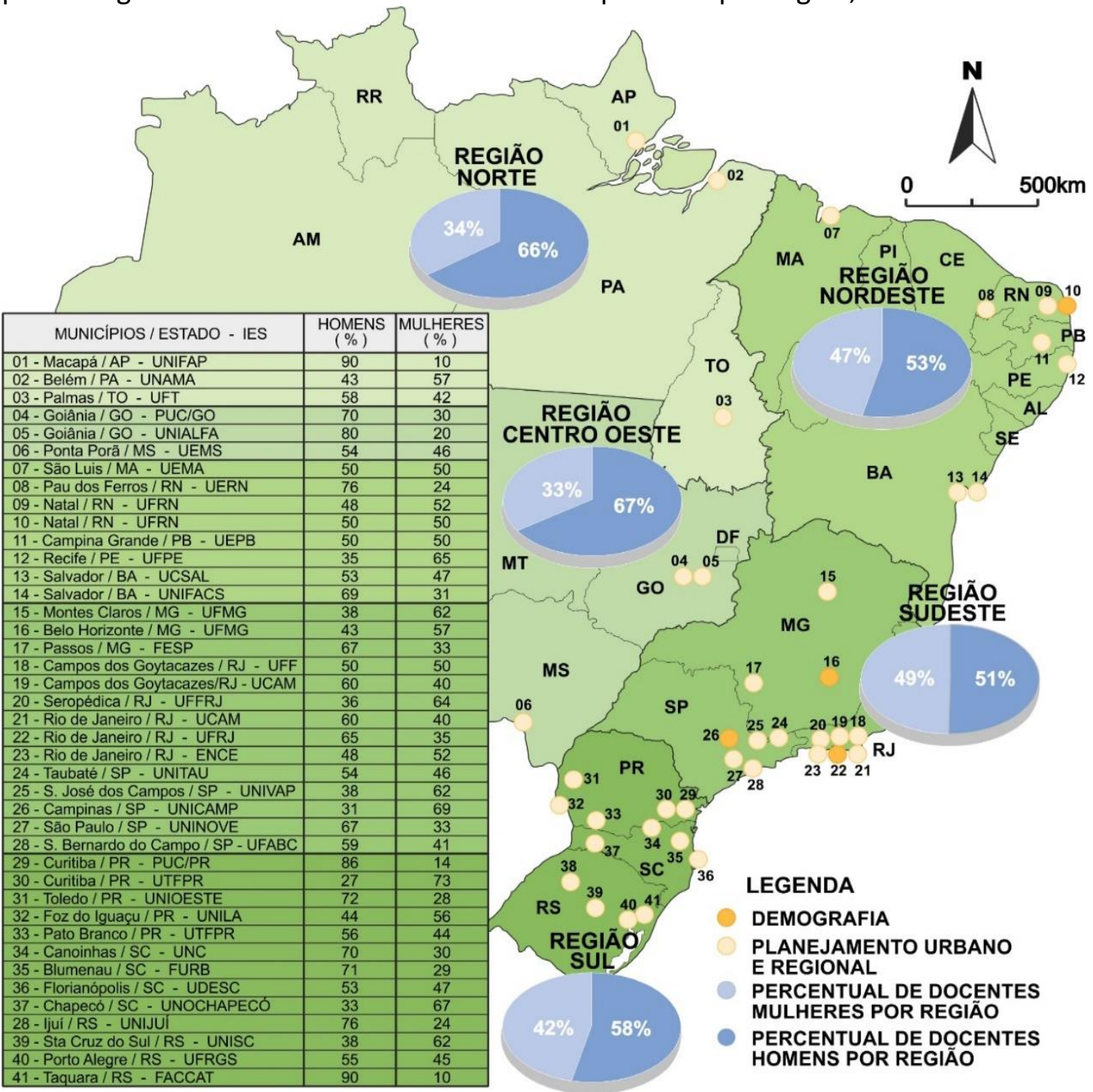

Fonte: Dados da pesquisa, figura elaborada por Ruy Lucas de Souza.

Diante deste quadro constatamos que, nos PPG em Planejamento Urbano e Regional/Demografia, as docentes mulheres aparecem em maior ou menor número, mas já contam com uma representatividade média de $43 \%$ no Brasil. Todavia, uma consulta rápida aos especialistas em Desenvolvimento Regional no Portal da Inovação (MCT, 2018) mostrou que entre os 10 primeiros especialistas, oito são homens e apenas duas são mulheres. Destes, seis estavam em PPG de Planejamento Urbano e Regional (indicados nas linhas em verde) e as duas mulheres não possuíam vínculo com os PPG em questão (Quadro 1, abaixo). 
Quadro 1 - Especialistas em Desenvolvimento Regional, Brasil, 2018

\begin{tabular}{|c|c|c|c|c|c|c|}
\hline \multirow[t]{2}{*}{ № } & \multirow[t]{2}{*}{ Especialista } & \multirow[t]{2}{*}{$\begin{array}{l}\text { Formação } \\
\text { básica }\end{array}$} & \multirow[t]{2}{*}{ Vínculo } & \multicolumn{3}{|c|}{$\begin{array}{l}\text { Palavras-chave } \\
\text { Frequência }\end{array}$} \\
\hline & & & & D & $\mathbf{R}$ & DR \\
\hline 1 & $\begin{array}{l}\text { Jandir Ferrera de } \\
\text { Lima }\end{array}$ & $\begin{array}{l}\text { Ciências } \\
\text { Econômicas }\end{array}$ & $\begin{array}{l}\text { Universidade Estadual do Oeste do } \\
\text { Paraná }\end{array}$ & 719 & 816 & 342 \\
\hline 2 & Ivo Marcos Theis & $\begin{array}{l}\text { Ciências } \\
\text { Econômicas }\end{array}$ & Universidade Regional de Blumenau & 637 & 338 & 217 \\
\hline 3 & $\begin{array}{l}\text { Edson A. de A. Q. } \\
\text { Oliveira }\end{array}$ & $\begin{array}{l}\text { Ciências } \\
\text { Econômicas }\end{array}$ & Universidade de Taubaté & 577 & 287 & 249 \\
\hline 4 & $\begin{array}{l}\text { Maria A. de } \\
\text { Castilho }\end{array}$ & História & Universidade Católica Dom Bosco & 711 & 0 & 0 \\
\hline 5 & $\begin{array}{l}\text { Gildasio R. } \\
\text { Teixeira }\end{array}$ & Geografia & Não consta & 1069 & 23 & 0 \\
\hline 6 & $\begin{array}{l}\text { Valdir Roque } \\
\text { Dallabrida }\end{array}$ & Geografia & Universidade do Contestado & 464 & 207 & 85 \\
\hline 7 & $\begin{array}{l}\text { Pedro L. } \\
\text { Buttenbender }\end{array}$ & Administração & $\begin{array}{l}\text { Universidade Regional do Noroeste } \\
\text { do Estado do Rio Grande do Sul }\end{array}$ & 570 & 142 & 0 \\
\hline 8 & $\begin{array}{l}\text { Alfredo K. O. } \\
\text { Homma }\end{array}$ & Agronomia & $\begin{array}{l}\text { Empresa Brasileira de Pesquisa } \\
\text { Agropecuária }\end{array}$ & 655 & 89 & 0 \\
\hline 9 & Edemar Rotta & Filosofia & Universidade da Fronteira Sul & 365 & 244 & 0 \\
\hline 10 & $\begin{array}{l}\text { Helena de C. de } \\
\text { Lorenzo }\end{array}$ & Ciências Sociais & $\begin{array}{l}\text { Universidade Estadual Paulista Júlio } \\
\text { de Mesquita Filho e Centro } \\
\text { Universitário de Araraquara }\end{array}$ & 514 & 150 & 0 \\
\hline
\end{tabular}

Fonte: Dados da pesquisa (MCT, 2018).

Apesar de ser um critério quantitativo (baseado na frequência das palavras-chave), indica que as docentes mulheres que estão nos PPG de Planejamento Urbano e Regional/Demografia não aparecem entre os dez maiores especialistas brasileiros em desenvolvimento regional. Mas reconhecemos que outros critérios qualitativos e quantitativos devem se somar a este. O que precisamos considerar é a reflexão sobre:

[...] como os indivíduos se tornaram quem são e dos limites desiguais para atuarem, individual e coletivamente. Em outras palavras, a vida doméstica, em um conjunto diferenciado de práticas que se estende da divisão sexual do trabalho à economia política dos afetos, da responsabilização desigual pelo cotidiano da vida à norma heterossexual, é desconsiderada como fator que define as possibilidades de atuação na vida pública. (BIROLI, 2018, p. 11).

Em 2018 elas representam 43\% dxs docentes em PPG em Planejamento Urbano e Regional e Demografia, mas ainda aparecem tão pouco nas referências e citações. Por isso entendemos que cabe aprofundarmos a pesquisa sobre essas mulheres, as dificuldades que enfrentam e avanços, e suas contribuições para o desenvolvimento regional. 


\section{Nossas inspirações (referencial teórico metodológico)}

No intuito de pesquisar as mulheres que pensam e fazem o desenvolvimento regional estamos construindo um modelo de análise que articula desenvolvimento regional, gênero/mulheres e pensamento social.

\subsection{Desenvolvimento + Região}

O discurso do desenvolvimento, disseminado a partir da década de 1940, inculcou a ideia de que o modo de produção industrial e a acumulação de bens materiais são sinônimo de sucesso e qualidade de vida. O que se pensou e se fez em nome do desenvolvimento foi incluir territórios não capitalistas nos circuitos de acumulação de capital, transformar seres humanos em merxs consumidorxs, camponesxs em trabalhadorxs assalariadxs, bens naturais em commodities, propriedade coletiva em privada (LANG, 2016).

Definitivamente não é este o desenvolvimento que queremos para nossas regiões. De que concepção de desenvolvimento partimos? Por quê? Para quê? Para quem? Considerando que os conceitos de desenvolvimento e região passam a significar o conhecimento e as experiências históricas que adotamos como referência. Os conceitos nos trazem muitos limites, mas sobretudo precisam nos trazer perguntas, textos e contextos (BUTZKE; THEIS; MANTOVANELLI JÚNIOR, 2018).

Somamos aos questionamentos sobre desenvolvimento, alguns questionamentos sobre região: "como se concebe a região? No que consiste essa ficção bem fundamentada chamada região? Quem faz a região? Como os grupos sociais ocupam as posições diferenciadas no espaço social? De que estratégias se valem?" (RENK, 2004, p. 7).

Os conceitos, região e desenvolvimento, trazem significados e experiências de outros espaços e tempos (eurocêntricos) que se impõem aos nossos espaços e tempos. Todavia, se os conceitos unificam em si um conjunto de significados e contém experiências históricas, podemos recuperar os significados e as experiências negados (BUTZKE; THEIS; MANTOVANELLI JÚNIOR, 2018).

A ideia é romper com a reflexão e prática voltadas a experiências de desenvolvimentos alternativos em regiões limitadas por narrativas hegemônicas situadas no espaço e no tempo. Questionar os conceitos é um primeiro passo na reflexão e prática de alternativas de 
desenvolvimento e de alternativas à fiç̧ão chamada região.

\subsection{Desenvolvimento Regional + Gênero/Mulheres}

Gênero é o termo utilizado para designar as relações sociais entre os sexos, é um conjunto de relações e não um atributo individual; e envolve relações de poder. O uso do termo "gênero" pode incluir o sexo, mas não é determinado por ele nem pela sexualidade. Seu uso faz parte da tentativa de enfatizar a incapacidade das teorias existentes de explicar as desigualdades entre homens e mulheres. Essas desigualdades têm seu lugar nos diferentes espaços e tempos (BUTLER, 2003; SCOTT, 1995).

Os estudos de gênero se desenvolveram em algumas direções. A primeira, diz respeito a forma como a mulher assume um modo de estar no mundo. A segunda é a do gênero como forma de hierarquização, de divisão sexual do trabalho. "O gênero opera como uma estrutura de poder, da mesma forma que a classe, a raça ou a cultura. (...) O conceito de gênero identifica os espaços materiais e simbólicos nos quais as mulheres têm uma posição de desvantagem social" (BEDÍA, 2014, p. 10).

Torna-se necessário problematizar as categorias de gênero que sustentam as hierarquias e a heterossexualidade. A tarefa consiste em centrar e descentrar as definições de falocentrismo e heterossexualidade compulsória existentes em nossa sociedade. O reconhecimento da posição da mulher no desenvolvimento está intimamente ligado com a posição da mulher no sistema global de produção (BUTLER, 2003; PEET; HARTWICK, 2015).

O capitalismo utiliza as relações de gênero para produzir um exército de reserva, enquanto elas realizam trabalho não pago em suas casas como forma de manter as corporações (PEET; HARTWICK, 2015). “Ao invés de um gesto linguístico auto limitativo que garanta a alteridade ou a diferença das mulheres, o falocentrismo oferece um nome para eclipsar o feminino e tomar o seu lugar." (BUTLER, 2003, p. 33).

Os estudos de gênero têm a possibilidade de transformar os paradigmas disciplinares. "As pesquisadoras feministas assinalaram desde o início que o estudo das mulheres não acrescentaria somente novos temas, mas que iria igualmente impor um reexame crítico das premissas e dos critérios do trabalho científico existente.". (SCOTT, 1995, p. 73).

Precisamos considerar que as epistemologias, as ciências e a compreensão de gênero estão espacialmente e historicamente localizadas. 
Desse ponto de vista, cada epistemologia alternativa - feminista, terceiro mundista, homossexual, operária - indica as condições históricas que produzem as oposições conceituais a serem superadas, mas não gera conceitos universais nem objetivos políticos. Como o gênero é também uma classe e uma categoria racial em culturas estratificadas segundo classe, raça e, também, gênero, a experiência isolada de uma mulher não pode servir de base para concepções e políticas que nos emanciparão a todas da hierarquia de gênero. (HARDING, 1993, p. 23).

Então, é por aí que caminhamos. Articulando desenvolvimento/região com as categorias de gênero e de mulheres como categorias abertas e não universais.

\subsection{Desenvolvimento + Gênero/Mulheres + Pensamento Social}

O pensamento social é um processo de reflexão da sociedade sobre ela mesma. É um pensamento em movimento, marcado histórica e geograficamente. Nossa imaginação é fertilizada por ele (MAIA, 2010).

O estudo do pensamento social pode incluir pesquisas sobre as tradições intelectuais, culturais, sociais e políticas. Hoje se preocupa com questões contemporâneas e, além dos grandes temas relacionados a formação do Estado-Nação, inclui questões ligadas a cidadania, cultura política, modernidade e mudança social. Abre espaço também para diferentes modalidades de produtores e de produção intelectual e artística e cultural. Soma-se aí: “O interesse por novas clivagens como as de gênero, idade, religião e raça e suas inflexões no pensamento social e na produção cultural.". (SCHWARCZ; BOTELHO, 2011, p. 12).

Se antes a preocupação era mais na constituição social das ideias, hoje interessa a reflexão e ação de grupos sociais na construção do próprio social (SCHWARCZ; BOTELHO, 2011). Aqui entra nossa preocupação com o pensamento social das mulheres.

A intenção não é de encontrar uma essência singular do pensamento social em relação ao pensamento europeu ou estadunidense, "mas sim de evidenciar as geografias desse violento encontro, cujos efeitos se disseminaram pelo continente." (MAIA, 2010, p. 71). Mostrar a complexidade geográfica e intelectual da produção feminina em sua relação com o desenvolvimento regional. Nos aproximando do trabalho pela margem, tão caro a Florestan Fernandes (GOHN, 2005). Na Figura 2, na sequência, apresentamos a tessitura entre os conceitos que utilizamos. 
Figura 2 - Modelo de análise

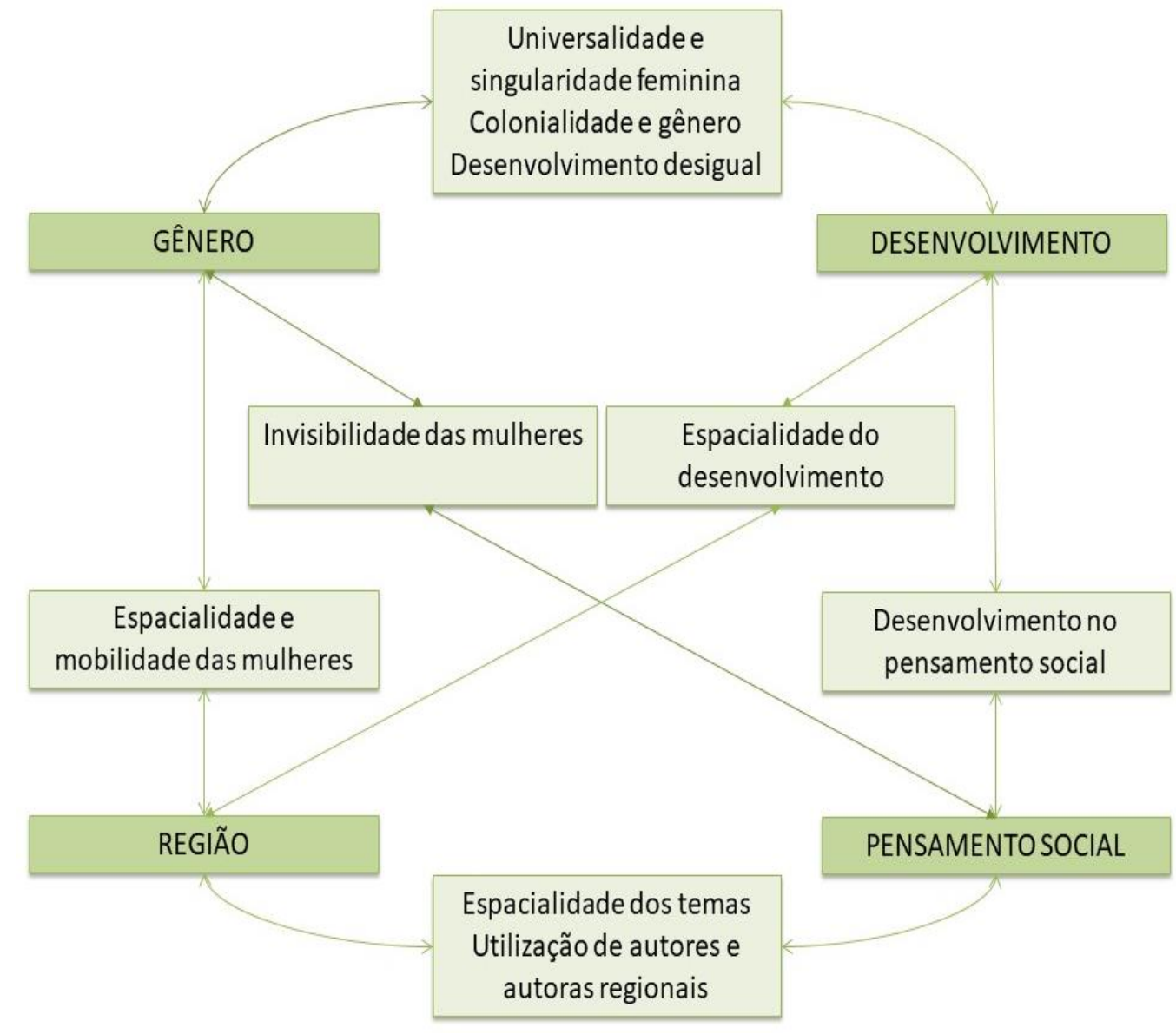

Fonte: Elaboração própria.

Consideramos que o modelo de análise serve como um fio condutor para nosso trabalho, mas as particularidades dos temas, dos tempos e dos recortes deve trazer movimento ao modelo.

\section{Agenda de Pesquisa: o olhar feminino no desenvolvimento regional}

O NPDR vem, nos últimos anos, fazendo um esforço para estudar o pensamento social brasileiro (LASTA, 2016; THEIS; BUTZKE, 2017) e o pensamento social latino-americano (BUTZKE; MANTOVANELLI JÚNIOR., THEIS, 2016; BUTZKE; THEIS; MANTOVANELLI JÚNIOR, 2017; idem, 2018). O Grupo entende que a reflexão/ação voltada ao desenvolvimento regional exige um conhecimento do que pensam e fazem os homens e mulheres que aqui viveram e vivem. $\mathrm{O}$ oferecimento de disciplinas sobre pensamento social brasileiro e latino-americano no âmbito do PPGDR também faz parte deste esforço.

Tendo como abrigo o PPGDR e NPDR e o tema mais amplo do desenvolvimento regional 
e do pensamento social, caminhamos na direção da construção de um recorte mais específico. Nossas conversas sobre o Projeto Colaborativo levaram ao desenho que segue (Figura 3), indicando os recortes espaciais (quadros em verde mais escuro) e suas articulações dentro dos recortes (quadros em verde mais claro). Indicamos América Latina, Brasil e Santa Catarina e a preocupação com as mulheres nas regiões, na sua relação com o desenvolvimento regional e na reflexão/ação sobre e com as mulheres.

Figura 3 - Delineamento dos temas de pesquisa e recorte espacial

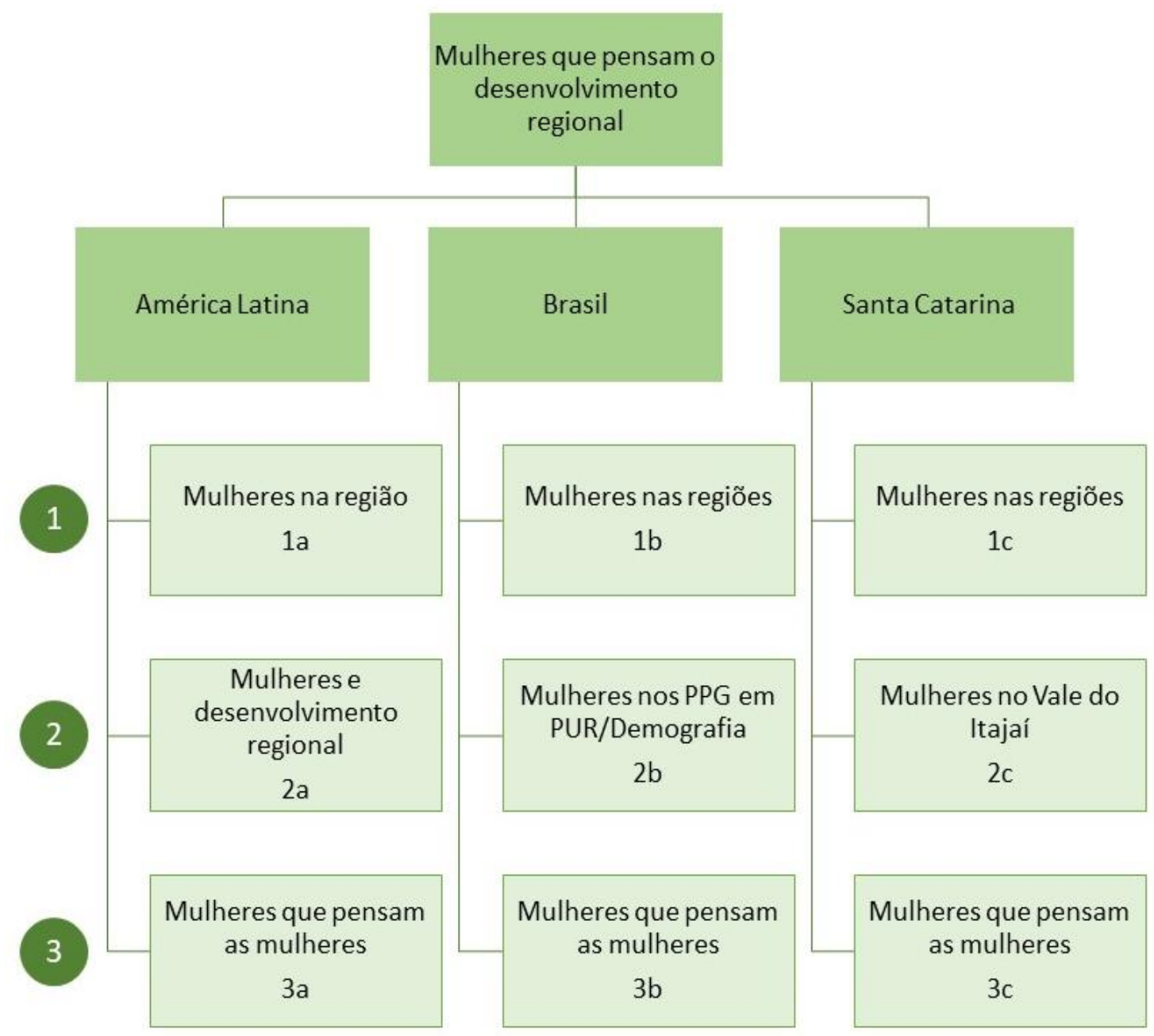

Fonte: Elaboração própria.

Como o Projeto Colaborativo está sendo desenhado desde fins de 2017 contamos apenas com três pesquisas concluídas e com duas pesquisas em curso. Indicamos, no Quadro 2, os trabalhos/pesquisas, modalidade, articulação com o Projeto Colaborativo através do número, letra e ano. Temos um Trabalho de Conclusão de Curso concluído (NEGHERBON, 2017), quatro projetos de Iniciação Científica (dois concluídos e dois em andamento) e um projeto de extensão. 
Quadro 2 - Relação de trabalhos/pesquisa relacionados ao Projeto Colaborativo, modalidade, articulação e ano

\begin{tabular}{|c|c|c|c|}
\hline Título do Trabalho/Pesquisa & Modalidade & $\begin{array}{l}\text { Articulação com } \\
\text { o Projeto } \\
\text { Colaborativo }\end{array}$ & Ano \\
\hline $\begin{array}{l}\text { O olhar feminino sobre o papel da mulher no } \\
\text { desenvolvimento do Vale do Itajaí }\end{array}$ & $\begin{array}{l}\text { Trabalho de Conclusão } \\
\text { de Curso }\end{array}$ & $2 c$ e $3 c$ & 2017 \\
\hline $\begin{array}{l}\text { Contribuições do pensamento social ao debate } \\
\text { sobre desenvolvimento regional, gênero e raça na } \\
\text { América Latina }\end{array}$ & Iniciação Científica & 1a, 2a e $3 a$. & $\begin{array}{l}2018 \\
2019\end{array}$ \\
\hline $\begin{array}{l}\text { Mulheres que pensam o desenvolvimento na } \\
\text { América Latina: Contribuições presentes nas } \\
\text { Antologias do Pensamento Social Latino- } \\
\text { Americano e Caribenho publicadas pelo Conselho } \\
\text { Latino-Americano de Ciências Sociais no período de } \\
2015 \text { a } 2017\end{array}$ & Iniciação Científica & 1a, 2a e $3 a$. & $\begin{array}{l}2018 \\
2019\end{array}$ \\
\hline $\begin{array}{l}\text { Mulheres que pensam o desenvolvimento na } \\
\text { América Latina: Contribuições presentes nas } \\
\text { Antologias do Pensamento Social Latino- } \\
\text { Americano e Caribenho publicadas pelo Conselho } \\
\text { Latino-Americano de Ciências Sociais no período de } \\
2015 \text { a } 2017\end{array}$ & $\begin{array}{l}\text { Iniciação Científica e } \\
\text { Pesquisa sem fomento } \\
\text { externo }\end{array}$ & 1a, 2a e $3 a$. & $\begin{array}{l}2018 \\
2020\end{array}$ \\
\hline $\begin{array}{l}\text { Contribuições dos estudos de gênero ao } \\
\text { desenvolvimento regional: Atuação e produção } \\
\text { intelectual de docentes dos } \\
\text { Programas de Pós-Graduação em Planejamento } \\
\text { Urbano e Regional na região Sul do Brasil }\end{array}$ & $\begin{array}{l}\text { Iniciação Científica e } \\
\text { Pesquisa sem fomento } \\
\text { externo }\end{array}$ & $1 b, 2 b$ e $3 b$ & $\begin{array}{l}2019 \\
2020\end{array}$ \\
\hline $\begin{array}{l}\text { Representações sociais da migração na região do } \\
\text { Vale do Itajaí no período recente numa perspectiva } \\
\text { de gênero e raça }\end{array}$ & Iniciação Científica & $1 c$ e $2 c$. & $\begin{array}{l}2019 \\
2020\end{array}$ \\
\hline $\begin{array}{l}\text { Cultura e vida social em movimento nas pinturas e } \\
\text { rendas de agulha: Proposta de educação } \\
\text { patrimonial no Museu } \\
\text { da Família Colonial de Blumenau }\end{array}$ & Extensão & $1 c$ e $2 c$. & $\begin{array}{l}2019 \\
2020\end{array}$ \\
\hline
\end{tabular}

Fonte: Elaborada pelos autores.

O Projeto Colaborativo Mulheres que pensam o desenvolvimento regional conta com uma página eletrônica: mulheresnodesenvolvimentoregional.com. Desde a sua criação, em 25 novembro de 2017, o site já recebeu 796 visitantes, 2362 visualizações de 17 países diferentes. A nossa intenção é divulgar os resultados parciais e finais a fim de entrar em contato com mais pessoas que se aproximam do tema. Esperamos que num futuro próximo possamos construir novos projetos e compartilhar conhecimentos com mais pessoas e grupos do Brasil e da América Latina. 


\section{Considerações finais}

O objetivo desse artigo foi o de apresentar o referencial teórico-metodológico do Projeto Colaborativo e elementos para a formação de uma agenda de pesquisa. O Projeto se insere no esforço mais amplo do NPDR/PPGDR de pensar o desenvolvimento regional a partir das contribuições de homens e mulheres que pensaram a América Latina, Brasil, Santa Catarina, Vale do Itajaí.

Nossa intenção com o Projeto Colaborativo é de tornar mais visível o esforço das mulheres latino-americanas e brasileiras em pensar e questionar o desenvolvimento regional e; de tornar mais visível o esforço das pesquisadoras na área do Planejamento Urbano e Regional e Demografia nessa mesma direção. A sistematização do referencial teórico-metodológico e da agenda de pesquisa é uma tentativa de compartilhar intenções que foram organizadas inicialmente por um pequeno coletivo, que espera a união de mais pessoas interessadas no tema. O Projeto Colaborativo está em construção. E é a partir de diferentes contatos, olhares ou contribuições que ele vai se delineando.

Conhecer a nossa história, das mulheres que contribuíram para escrevê-la, é fundamental para que nos posicionemos em relação ao que somos e fazemos. A reflexão sobre desenvolvimento regional, gênero/mulheres e pensamento social se insere neste esforço. As mulheres pensam o desenvolvimento regional? Sim, elas pensam! Cabe a nós, a tentativa de recuperar esse pensamento, como parte da nossa história, que continua sendo escrita.

\section{Referências}

BEDÍA, Rosa Cobo. Aproximações à teoria crítica feminista. Boletim do Programa de formação no 1, ano 1, junho 2014. Disponível em:

https://www.cladem.org/images/pdfs/publicaciones/regionales/feminismo-por/BOLETINCLADEM-VERSION-PORTUGUES.pdf. Acesso em: 14/05/2017.

BIROLI, Flávia. Gênero e desigualdades. Limites da democracia no Brasil. São Paulo: Boitempo, 2018.

BUTLER, Judith. Problemas de gênero. Feminismo e subversão da identidade. Rio de Janeiro: Civilização Brasileira, 2003.

BUTZKE, Luciana; MANTOVANELLI JÚNIOR; Oklinger; THEIS, Ivo Marcos. Afinal, desenvolvimento regional serve para quê? Reflexões a partir da Sociologia da libertação de Fals Borda e da Sociologia da Exploração de Casanova. Redes, v. 21, no 3, p. 306-318, set./dez. 2016.

BUTZKE, Luciana; THEIS, Ivo Marcos; MANTOVANELLI JÚNIOR; Oklinger. O entre-lugar da 
sociologia regional na América Latina. Anais do XXXI Congreso Alas, Uruguay, 3 a 8 de dezembro 2017.

BUTZKE, Luciana; THEIS, Ivo Marcos; MANTOVANELLI JÚNIOR; Oklinger. Existe alguma região para desenvolver? Um questionamento desde o pensamento social latino-americano. Revista Brasileira de Gestão e Desenvolvimento Regional, v. 14, n. 2, 2018, p. 91-106. Disponível em: http://www.rbgdr.net/revista/index.php/rbgdr/article/view/3586/660. Acesso em: 24/03/2018.

GOHN, Gabriel. Florestan Fernandes e o radicalismo plebeu em Sociologia. Estudos Avançados, $19,55,2005$, p. 245-250.

HARDING, Sandra. A instabilidade das categorias analíticas na teoria feminista. Estudos feministas, n. 1, 1993, p. 7-31.

LANG, Miriam. Introdução: alternativas ao desenvolvimento. In: DILGER, Gerhard; LANG; Miriam; PEREIRA FILHO, Jorge (Orgs.). Decolonizar o imaginário. Debates sobre pósextrativismo e alternativas ao desenvolvimento. São Paulo: Fundação Rosa Luxemburgo, 2016, p. 25-44.

LASTA, Tatiane Thais. A contribuição do pensamento social brasileiro para a questão regional neste início de século XXI. 2016. 199 f., il. Dissertação (Mestrado em Desenvolvimento Regional) - Programa de Pós-Graduação em Desenvolvimento Regional, Centro de Ciências Humanas e da Comunicação, Universidade Regional de Blumenau, Blumenau, 2016. Disponível em: http://www.bc.furb.br/docs/DS/2016/361551 1 1.pdf. Acesso em: 19/05/2018.

MAIA, João Marcelo Ehlert. O pensamento social brasileiro e a imaginação pós-colonial. Revista Estudos Políticos, no 0, 2010/1, p. 64-78.

MCT - MINISTÉRIO DA CIÊNCIA E DA TECNOLOGIA. Portal da Inovação. Disponível em: http://www.portalinovacao.mct.gov.br/pi/\#/pi. Acesso em: 15 maio de 2018.

NEGHERBON, Caroline Laíza. O olhar feminino sobre o papel da mulher no desenvolvimento do Vale do Itajaí. 2017. Trabalho de Conclusão de Curso, Ciências Sociais, Universidade Regional de Blumenau, Blumenau, 2017.

NPDR. Quem somos. Disponível em: https://npdr.wordpress.com/sobre/. Acesso em: 19 maio 2018.

OROZCO, Amaia Pérez. Subversión feminista de la economia. Aportes para un debate sobre el conflito capital-vida. Madrid: Traficantes de sueños, 2017.

PEET, Richard; HARTWICK, Elaine. Theories of development. Contentions, Arguments, Alternatives. 3a ed. New York: The Guilford Press, 2015.

RENK, Arlene. Narrativas da diferença. Chapecó: Argos, 2004.

SCOTT, Joan. Gênero: uma categoria útil de análise histórica. Educação \& Realidade, v. 15, n. 2, jul./dez. 1995, p. 71-98.

SCHWARCZ, Lilia Moritz; BOTELHO, André. Pensamento social brasileiro, um campo vasto ganhando forma. Lua Nova, São Paulo, 82: 11-16, 2011.

THEIS, Ivo Marcos; BUTZKE, Luciana. Desenvolvimento regional no Brasil: inserção subordinada na economia mundial e fragmentação do território. Anais do XVII ENANPUR, São Paulo, 2017. 